\title{
Effects of Vasoactive Agents on Intestinal Oxygen Consumption and Blood Flow in Dogs
}

\author{
Wieslaw Pawlik, A. P. Shepherd, and Eugene D. Jacobson \\ From the Department of Physiology, The University of Texas Medical School \\ at Houston, Houston, Texas 77025
}

A B STRACT A comparison study of several vasoconstrictor and vasodilator agents was conducted measuring changes in intestinal blood flow and oxygen consumption during 10 -min periods of intra-arterial infusion. Blood flow was measured in a branch of the superior mesenteric artery of anesthetized dogs with an electromagnetic blood flow meter, and the arteriovenous oxygen content difference across the gut segment was determined photometrically. Vasopressin (4 $\times 10^{-3}$ and $7 \times 10^{-4} \mathrm{U} / \mathrm{kg}$-min) diminished blood flow 60 and $28 \%$ and reduced oxygen consumption 54 and $22 \%$, respectively (all $P<0.001$ ). In a dose which did not lower blood flow, vasopressin still caused a decline in oxygen consumption $(P<0.01)$. Epinephrine $\left(5 \times 10^{-2} \mu \mathrm{g} / \mathrm{kg}\right.$-min $)$ decreased blood flow $19 \% \quad(P$ $<0.001$ ) but did not reduce oxygen consumption. After $\beta$-adrenergic blockade, however, the same dose of epinephrine decreased blood flow $41 \%$ and oxygen consumption $33 \%$ (both $P<0.001$ ). Responses to angiotensin II, calcium chloride, and prostaglandin $F_{2 \alpha}$ resembled effects of vasopressin rather than those of epinephrine, namely decreased blood flow and decreased oxygen consumption. The vasodilator agents, prostaglandin $\mathrm{E}_{1}$, isoproterenol, and histamine, increased ( $P$ $<0.001)$ both blood flow $(130,80$, and $98 \%$, respectively) and oxygen consumption $(98,64$, and $70 \%$, respectively). Vasopressin, angiotensin II, calcium chloride, and prostaglandin $\mathrm{F}_{2 \alpha}$ appear to contract arteriolar and precapillary sphincteric smooth muscle indiscriminately to evoke both intestinal ischemia and hypoxia. Epinephrine is the exceptional constrictor in this case, producing diminished blood flow without a reduction in oxygen uptake.

Dr. Pawlik's present address is the Institute of Physiology, Medical Academy of Krakow, Krakow, Poland; Dr. Shepherd's present address is Department of Physiology, The University of Texas Medical School at San Antonio, San Antonio, Tex. 78284.

Received for publication 1 November 1974 and in revised form 5 March 1975.

\section{INTRODUCTION}

Recently, vasoconstrictor drugs, most notably intraarterial vasopressin, have been employed in the management of massive gastrointestinal hemorrhage, especially from esophageal varices (1). The objective of such therapy is to reduce blood flow through the splanchnic vessels to minimize or stop bleeding. Such therapy in hemorrhagic states is associated with high mortality rates and with intestinal infarction (2). One possible explanation for the deleterious effects of vasopressin is that it could reduce the delivery of oxygen to intestinal tissues. If intestinal blood flow is reduced by mechanical means rather than by vasoconstrictors (e.g. by reducing perfusion pressure), a concomitant increase in oxygen extraction occurs so that oxygen uptake (the product of arteriovenous oxygen difference and blood flow) is unaltered except at critically low blood flow rates (3). Reducing blood flow with vasoconstrictors is not equivalent to reducing blood flow mechanically. Vasoconstrictors produce other microvascular effects besides a greater resistance to blood flow.

Exogenous vasoconstrictors and sympathetic stimulation constrict all three of the functionally defined seriescoupled elements within the intestinal microvasculature: the resistance vessels $(4,5)$, the capacitance vessels $(4,6)$, and the precapillary sphincters which determine the number of capillaries or exchange vessels perfused at a given moment (4-7). However, the response of one of these functionally defined "effectors" to an exogenous vasoconstrictor may be antagonized by local blood flow-controlling mechanisms such as vasodilator metabolites or tissue hypoxia (7). Thus, the resistanceexchange-capacitance response pattern produced by exogenous vasoconstrictors depends upon the balance reached between the vasoconstrictor and the local vasodilator factors at each vascular effector.

By means of a computer model of the intestinal microcirculation (7), we recently predicted that nor- 
epinephrine and sympathetic stimulation would constrict precapillary sphincters to such an extent that the bloodto-tissue flux of oxygen would be limited by the diffusion parameters, e.g., capillary surface area and capillary-to-cell diffusion distance $(7,8)$. We tested this prediction in animal experiments by perfusing isolated loops of canine small bowel at a constant rate of blood flow (9). Sympathetic stimulation and intra-arterial norepinephrine depressed oxygen extraction in a frequency- or dose-dependent manner. When the extraction of the nonmetabolizable tracer, ${ }^{88} \mathrm{Rb}$, was determined, rubidium extraction and oxygen extraction were synchronously depressed by these adrenergic constrictors $(9,10)$. Since rubidium extraction is a valid index of the relative number of perfused capillaries (11), we concluded that norepinephrine and sympathetic stimulation reduced the density of the perfused capillary bed to such an extent that intestinal extractions of oxygen and rubidium were depressed despite constant flow perfusion.

Although these studies $(9,10)$ and more recent ones from our laboratory $(12,13)$ have shown that vasoconstrictors (sympathetic stimulation, norepinephrine, epinephrine, and vasopressin) reduce intestinal oxygen extraction, our data are not comparable to that from patients receiving vasoconstrictor therapy since our experiments were performed in denervated gut loops perfused at constant flow. We performed previous studies under constant flow to show clearly that these agents can alter intestinal oxygen uptake independently of their effects on blood flow, and because the rubidium technique requires constant flow (11). Constant blood flow, however, obscures the antagonism which local factors offer to vasoconstrictors since the accumulation of vasodilator metabolites or tissue hypoxia is minimized by constant flow. Thus, it is unwise to extrapolate from our data at constant flow to the more physiological condition of constant pressure perfusion.

The purpose of the present work has been to determine if vasoconstrictors reduce the oxygen uptake of intestinal loops perfused at constant pressure, and, if so, to determine to what extent the reduction in blood flow and the alterations in oxygen extraction account for the changes in oxygen uptake. We have investigated in particular the effects of vasopressin on intestinal hemodynamics and oxygen consumption and compared its effects with those of other mesenteric vasoconstrictor drugs (epinephrine, angiotensin II, calcium chloride, and prostaglandin $F_{2 \alpha}$ ) and with effects of vasodilator agents (prostaglandin $E_{1}$, isoproterenol, and histamine).

\section{METHODS}

Subjects of our experiments were 50 fasted mongrel dogs of either sex weighing $15-20 \mathrm{~kg}$ each. Animals were anesthe- tized with intravenous pentobarbital sodium $(30 \mathrm{mg} / \mathrm{kg})$. Supplemental doses of the agent were administered to maintain deep levels of anesthesia throughout all experiments.

Both femoral arteries and veins were exposed, one vein for injection of supplemental anesthetic and one artery for cannulation to monitor systemic arterial blood pressure, using a strain gauge transducer (Hewlett-Packard Co., Palo Alto, Calif., model $1280 \mathrm{C}$ ). Before the onset of experiments, arterial pressure exceeded $100 \mathrm{~mm} \mathrm{Hg}$ in all animals.

A terminal trunk of the superior mesenteric artery supplying a segment of distal ileum (50-100 g weight) was exposed via a midline laparotomy. The ends of the gut segment supplied by the vessel were ligated to block intramural collateral vessels. The probe of an electromagnetic blood flow transducer (Micron Instruments Inc., Los Angles, Calif.) of $1.5-2.0 \mathrm{~mm}$ size (ID) was implanted about the exposed artery and connected to an amplifier (Micron Instruments Inc.). A lateral branch of the artery was cannulated proximal to the probe for intra-arterial infusion of the vasoactive agents. No attempt was made to denervate the perfused gut segment.

A vein draining the intestinal segment was cannulated along with a femoral artery. A constant flow pump withdrew blood from each vessel, passed the blood through the venous and arterial cuvettes of an arteriovenous oxygen difference analyzer, and then returned the blood to the circulation via a femoral vein. This preparation has been described previously in detail (13).

Blood flow through the branch of the mesenteric artery was measured with precalibrated transducers. At the beginning and end of each experiment, we occluded the vessel distal to the transducer to provide a transient zero flow (14). At the end of each experiment the gut segment was excised and weighed. In 43 animals, mean flow ( $\pm S E$ ) was $34 \pm 7 \mathrm{ml} / \mathrm{min}$ per $100 \mathrm{~g}$ of tissue before the onset of drug infusion. Intestinal oxygen consumption was calculated as the product of the simultaneously measured arteriovenous oxygen content difference and the mean blood flow $(10,13)$. The mean rate of oxygen consumption was $2.4 \pm 0.5 \mathrm{ml}$ oxy$\mathrm{gen} / \mathrm{min}$ per $100 \mathrm{~g}$ tissue in these animals. These intestinal blood flow and oxygen consumption values agree with those reported elsewhere $(3,15)$.

Each drug was infused into the mesenteric artery for 10 min in each animal. The drugs employed, their commercial sources and doses, and the number of separate animal experiments are indicated in Table I. With vasoconstrictor agents a dose was usually selected which would reduce blood flow about $20-25 \%$; with vasopressin a more potent and a less potent dose were also studied. With the vasodilator drugs doses were selected to double blood flow approximately. In experiments with epinephrine and isoproterenol, we used propranolol comparing responses of intestinal oxygen consumption and blood flow with each catecholamine alone and with the same dose of epinephrine or isoproterenol after $\beta$-blockade with propranolol (0.1-0.3 $\mathrm{mg}$ injected intra-arterially). A total of 88 separate experiments were conducted in 43 dogs. No dogs were used twice for the same dose of a drug, except in experiments with propranolol.

Since each agent was infused directly into the mesenteric artery in small doses, there was far less effect upon systemic arterial pressure than upon mesenteric artery blood flow. The vasoconstrictor agents either increased systemic arterial pressure slightly $(<10 \mathrm{~mm} \mathrm{Hg})$ or had no effect, and the vasodilator drugs either decreased blood pressure slightly or had no effect. Therefore, the primary effect of each agent was considered to be a direct one upon the 

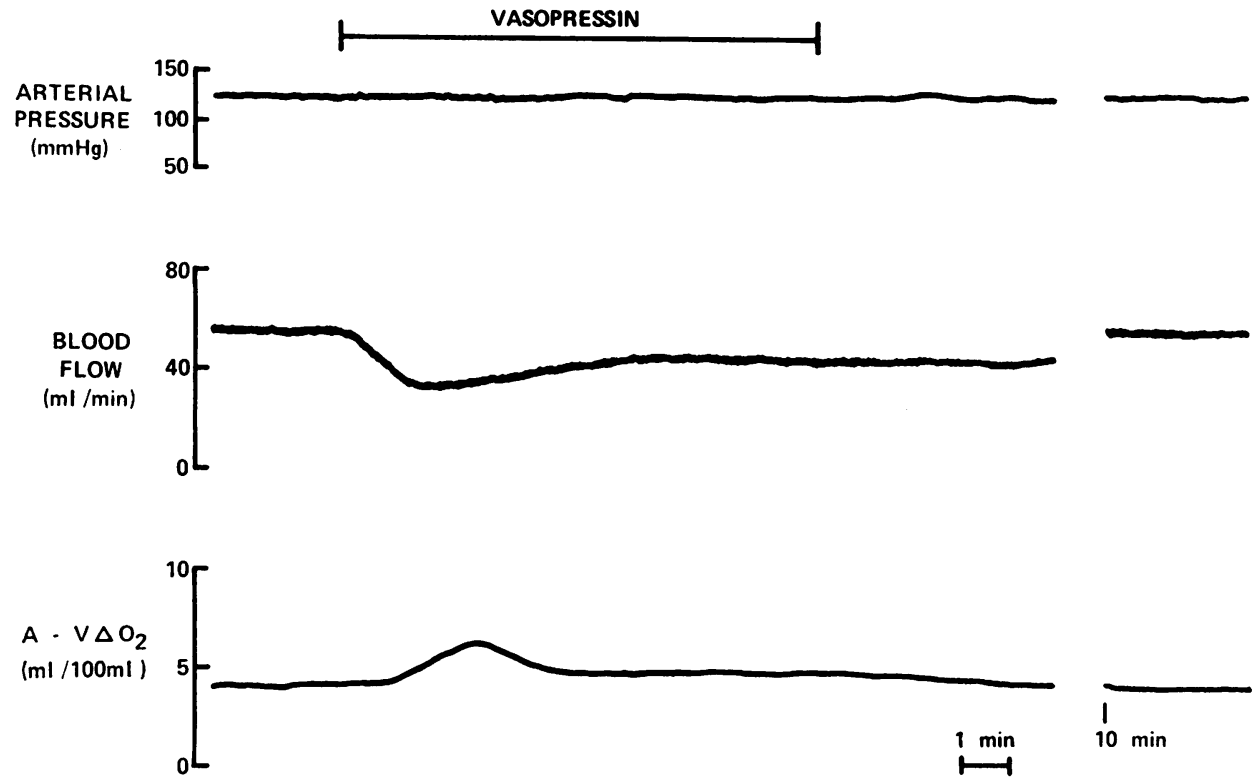

FiguRe 1 Effect of vasopressin infusion on systemic arterial pressure, mesenteric artery branch blood flow and arteriovenous oxygen difference across the intestinal circulation in one experiment. Since arterial pressure changed little, the effect of vasopressin on the local circulation is that of a direct constrictor agent. Note the reciprocal response of $A-V_{\Delta} O_{2}$ to the change in blood flow.

vascular bed under study rather than a reflex-induced effect. Furthermore, our data have not been expressed in terms

TABLE I

Agents Used in the Present Study

\begin{tabular}{|c|c|c|}
\hline Agent & $\begin{array}{l}\text { Intra-arterial } \\
\text { dose }\end{array}$ & $\begin{array}{l}\text { Number of } \\
\text { separate dog } \\
\text { experiments }\end{array}$ \\
\hline & $\begin{array}{c}\text { per kg body } \\
\text { wt/min }\end{array}$ & \\
\hline $\begin{array}{l}\text { Vasoconstrictors } \\
\text { Vasopressin } \\
\text { (Pitressin tannate, } \\
\text { Parke, Davis \& Co., }\end{array}$ & $4 \times 10^{-3} \mathrm{U}$ & 8 \\
\hline $\begin{array}{l}\text { Vasopressin } \\
\text { Vasopressin } \\
\text { Epinephrine } \\
\text { (Adrenalin chloride, } \\
\text { Parke, Davis \& Co.) }\end{array}$ & $\begin{array}{l}7 \times 10^{-4} \mathrm{U} \\
3 \times 10^{-4} \mathrm{U} \\
50 \mathrm{ng}\end{array}$ & $\begin{array}{l}7 \\
6 \\
9\end{array}$ \\
\hline $\begin{array}{l}\text { Epinephrine after } \\
\text { propranolol hydrochloride } \\
\text { (Inderal, Ayerst } \\
\text { Laboratories, New York) }\end{array}$ & & 9 \\
\hline $\begin{array}{l}\text { Laboratories, New York) } \\
\text { Angiotensin II } \\
\text { (Hypertensin, CIBA } \\
\text { Pharmaceutical Company, } \\
\text { Summit, N. J.) }\end{array}$ & $25 \mathrm{ng}$ & 7 \\
\hline $\begin{array}{l}\text { Calcium chloride } \\
\text { Prostaglandin F F } \\
\text { (The Upjohn Company, } \\
\text { Kalamazoo, Mich.) }\end{array}$ & $\begin{array}{l}300 \mu \mathrm{gg} \\
250 \mathrm{ng}\end{array}$ & $\begin{array}{l}7 \\
7\end{array}$ \\
\hline $\begin{array}{l}\text { Vasodilators } \\
\text { Prostaglandin } E_{1}\end{array}$ & $500 \mathrm{ng}$ & 7 \\
\hline $\begin{array}{l}\text { (The Upjohn Company) } \\
\text { Isoproterenol } \\
\text { (Isuprel, Winthrop } \\
\text { Laboratories, New York) }\end{array}$ & $500 \mathrm{ng}$ & 7 \\
\hline $\begin{array}{l}\text { Isoproterenol } \\
\text { after propranolol hydrochloride } \\
\text { Histamine acid phosphate } \\
\text { (Eli Lilly and Company. } \\
\text { Indianapolis, Ind.) }\end{array}$ & $500 \mathrm{ng}$ & $\begin{array}{l}7 \\
7\end{array}$ \\
\hline
\end{tabular}

of resistance, since resistance values would be approximately reciprocal to changes in blood flow.

Significance of changes was determined using the paired $t$ test with a confidence level of $5 \%$ or less. For each agent results have been presented graphically as a percent change of blood flow and of oxygen consumption from the control value obtained in the last minute before starting infusion of the drug (Figs. 2-5). The paired $t$ test was used to evaluate significance of changes from control.

\section{RESULTS}

Vasopressin was infused intra-arterially at three different dose rates: $4 \times 10^{-8}, 7 \times 10^{-4}$, and $3 \times 10^{-4} \mathrm{U} /$ $\mathrm{kg}$-min. Results from one experiment using the highest dose of vasopressin are reproduced in Fig. 1. The highest dose caused a $60 \%$ decrease $(P<0.001)$ in blood flow and a $54 \%$ decrease $(P<0.001)$ in oxygen consumption. The lowest dose caused no change in blood flow; however, oxygen consumption declined $6 \%$ $(P<0.01)$ with the lowest dose of vasopressin. These results appear in Fig. 2. Values indicated in this and succeeding figures were obtained during the steadystate phase of the infusion.

Intra-arterial epinephrine decreased intestinal blood flow $19 \%(P<0.001)$. Oxygen consumption was unchanged by epinephrine. After $\beta$-blockade with propranolol the same dose of epinephrine decreased blood flow $41 \%(P<0.001)$ and decreased oxygen consumption $33 \%(P<0.001)$. These results appear in Fig. 3. 


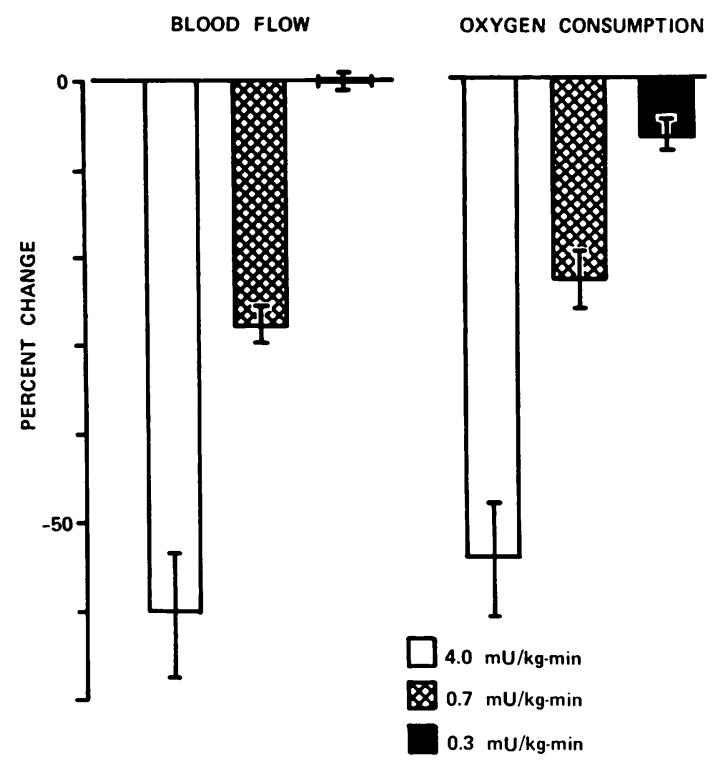

Figure 2 Effects of three doses of vasopressin on blood flow and oxygen consumption of the intestinal segment. Bars represent mean values ( $\pm \mathrm{SE}$ ) from each series of experiments. Note that the lowest dose of vasopressin significantly $(P<0.05)$ reduced oxygen consumption without altering blood flow. The values indicated are those obtained during the steady-state phase of the infusion.

Angiotensin II reduced blood flow and oxygen consumption 26 and $18 \%$, respectively (both $P<0.001$ ). Calcium chloride diminished both blood flow and oxygen consumption by $12 \%(P<0.05$ and 0.001 , respectively). Prostaglandin $\mathrm{F}_{2 \alpha}$ lowered blood flow $27 \%$ and oxygen consumption $21 \%$ (both $<0.001$ ). Values obtained with these constrictor agents are depicted in Fig. 4.

Prostaglandin $E_{1}$ increased blood flow $130 \%$ and oxygen consumption $98 \%$ ( $P<0.001$ for both). Isoproterenol raised blood flow $80 \%$ and oxygen consumption $64 \%$ (both $P<0.001$ ). After propranolol blockade, both responses to the same dose of isoproterenol were not significantly different from control. Histamine augmented blood flow $98 \%$ and oxygen consumption $70 \%$ ( $P<0.001$ for both). Values obtained with dilator drugs are indicated in Fig. 5.

\section{DISCUSSION}

The two most important structures of the intestinal microcirculation which regulate total blood flow to the gut and capillary blood flow, respectively, are the arteriolar smooth muscle and the muscle of the precapillary sphincters. More than half of the resistance to the total flow of blood through the gut occurs during passage of the blood through the arterioles (16). Small changes in the diameter of these vessels are translated

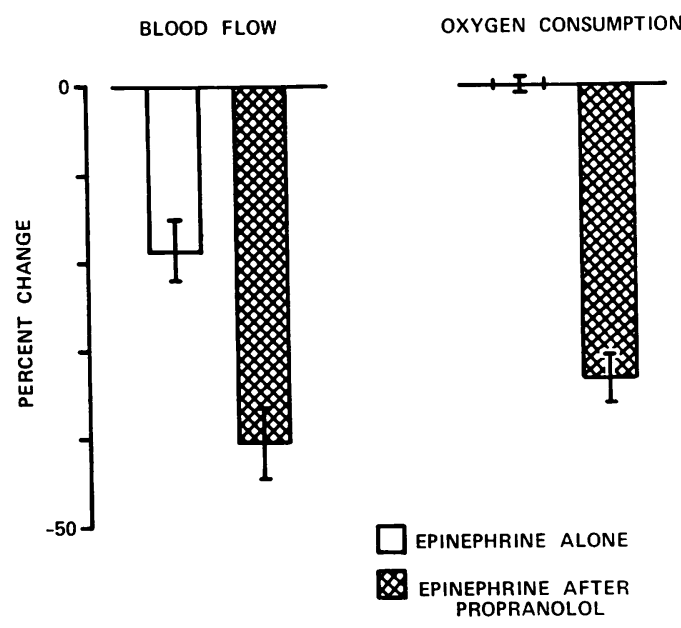

FigURE 3 Effects of epinephrine before and after propranolol on blood flow and oxygen consumption of the gut segment in nine experiments. After $\beta$-blockade epinephrine induced more severe vasoconstriction, and the oxygen-sparing capacity of the catecholamine was lost. The values indicated are those obtained during the steady-state phase of the infusion.

into large changes in blood flow through the superior mesenteric artery. However, it is also true under "resting" conditions that only one-third to one-fourth of the capillaries are open to the flow of blood at any moment in time (17). Thus, by identifying the diffusion parameters (surface area and diffusion distance), it becomes apparent that the density of the perfused capillary bed is a critical determinant of tissue oxygen extraction. Furthermore, our calculations indicate that changes in the density of the perfused capillary bed

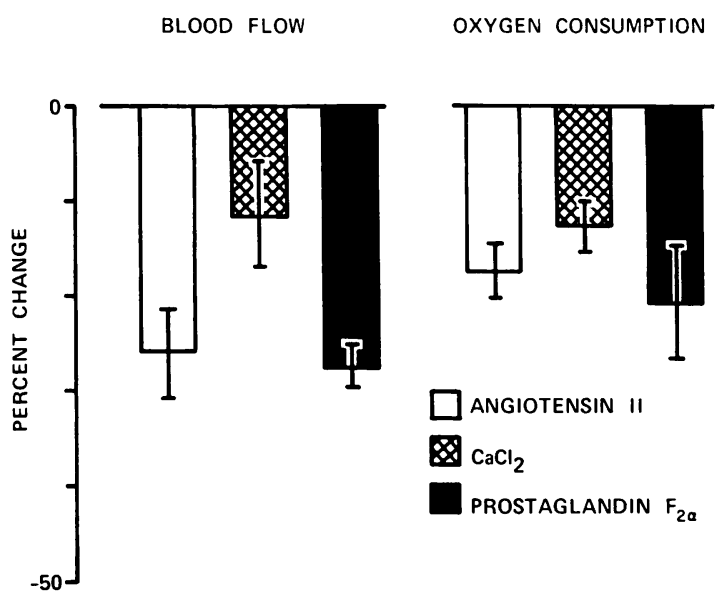

FIGURE 4 Effects of angiotensin II, calcium chloride, and prostaglandin $F_{2 \alpha}$ on blood flow and the rate of oxygen consumption of the intestinal segment. These three constrictors reduced both blood flow and oxygen consumption. The values indicated are those obtained during the steadystate phase of the infusion. 


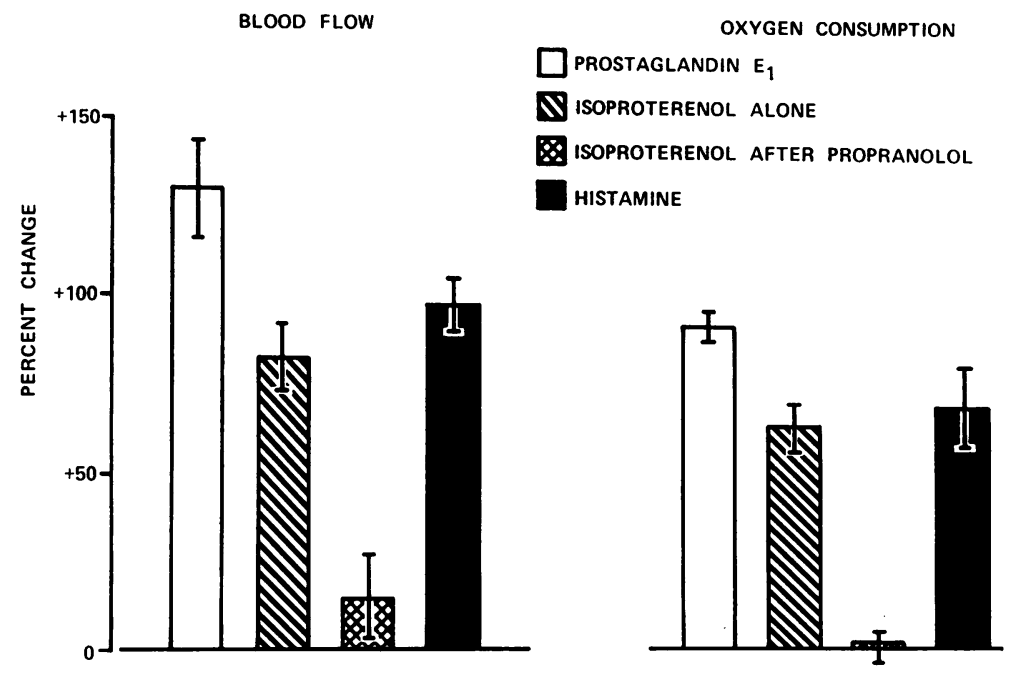

FIGURE 5 Effects of prostaglandin $E_{1}$, isoproterenol (before and after propranolol), and histamine on blood flow and oxygen consumption of perfused intestinal segments. The values indicated are those obtained during the steady-state phase of the infusion.

are as significant to oxygen delivery as are the changes in blood flow $(7,8,10)$. It also follows that a drug may cause a sizeable decrease in the total flow of blood to the gut without reducing the delivery of oxygen to the tissue, since extraction of oxygen can increase to compensate for the reduced total blood flow. If the agent constricts arteriolar smooth muscle selectively, without affecting the ability of the precapillary sphincters to regulate the diffusion parameters so as to increase oxygen extraction, intestinal oxygen consumption will not suffer until total blood flow is reduced to a critically low level $(3,7,10)$. Use of a drug with a selective constrictive action on arterioles would permit production of ischemia without imperiling the viability of the gut with hypoxia.

Unfortunately, the present study has shown that the most commonly employed vasoconstrictor in cases of severe gastrointestinal hemorrhage, namely vasopressin, may not possess this selectivity. Vasopressin reduced the oxygen uptake of gut loops perfused both at constant flow (12) and, as the present study shows, at constant pressure. In the present study, the lowest dose of vasopressin reduced oxygen uptake without lowering blood flow, whereas higher doses reduced both blood flow and oxygen consumption (Fig. 2). The changes in blood flow and oxygen uptake occurred quite rapidly (Fig. 1) and we interpret them as a vascular effect of vasopressin to lower oxygen delivery. However, an alternative explanation is that vasopressin might reduce the tissue demand for oxygen via a direct metabolic effect since vasopressin is known to depress electrolyte transport in vivo (18). We feel the metabolic explanation is less likely than the vascular one because the changes in oxygen consumption which occur when sugar-electrolyte or dinitrophenol solutions are placed in the lumen are much slower than are the vasopressin-induced changes in oxygen uptake (unpublished observations from our laboratory). In addition, vasopressin stimulates both the electrolyte absorption $(19,20)$ and the oxygen consumption (20) rate of isolated epithelia in which the vascular mechanism has been eliminated. Because reports conflict concerning vasopressin's transport effect in vivo $(18,21)$, it is not unlikely that vasopressin lowers blood flow and oxygen delivery. This, in turn, could lead to the diminished electrolyte transport seen in vivo.

In the present study all intestinal vasoconstrictors, except epinephrine, reduced both total blood flow to the gut and intestinal oxygen consumption. Thus, vasopressin, angiotensin II, calcium chloride, and prostaglandin $F_{2 \alpha}$ each evoked ischemia and hypoxia, approximately in parallel. In other studies we have found that cardiac glycosides (13), epinephrine, vasopressin (12), norepinephrine, and electrical stimulation of splanchnic sympathetic nerves $(9,10)$ depress oxygen extraction despite constant flow perfusion. In terms of identifying the responsive structures in the intestinal microcirculation which regulate total blood flow and the density of the perfused capillary bed, the aforementioned vasoconstrictors seemed to act on smooth muscle of both arterioles and precapillary sphincters, since rubidium extraction was also depressed.

Epinephrine is an exceptional vasoconstrictive agent. One explanation for the action of this agent would be that epinephrine constricted mesenteric arteriolar smooth muscle, thereby increasing the vascular re- 
sistance and reducing total blood flow to the gut, but in the dose used did not constrict the precapillary sphincters. Consequently, the nutrient circulation was preserved, and oxygen consumption was not depressed by epinephrine. In support of this possibility are findings of Zweifach (22) who showed in the rat mesenteric circulation under direct visualization that arteriolar smooth muscle contracted brickly to topical epinephrine but that precapillary sphincters were unresponsive.

An alternative explanation for effects observed with this catecholamine would be that epinephrine constricted precapillary sphincters but also increased tissue metabolism and lowered intracellular $\mathrm{Po}_{2}$, thereby increasing the capillary-to-cell oxygen gradient. This would explain our finding that epinephrine caused no decrease in oxygen consumption. This possibility is consistent with our finding in gut loops perfused at constant flow (12) that small doses of epinephrine caused an increase in both oxygen consumption and in the clearance of ${ }^{80} \mathrm{Rb}$. At this time, the mechanism whereby epinephrine maintained normal levels of oxygen consumption in the face of reduced blood flow to the gut is uncertain.

The ability of the $\beta$-adrenergic antagonist, propranolol, to abolish the oxygen-sparing properties of epinephrine was not unexpected, since norepinephrine reduced oxygen consumption in a constant-flow preparation $(9,10)$. In addition, when epinephrine increased oxygen uptake in gut loops at constant flow, propranolol caused the same dose of epinephrine to reduce oxygen consumption (12). One inference from our results is that the precapillary sphincter may contain a greater density of $\beta$-adrenergic receptors than does the arteriole. Thus, epinephrine, which can stimulate both $\alpha$ constrictor and $\beta$-dilator receptors, is able in some concentrations to constrict the arterioles without constricting and perhaps even dilating the precapillary sphincters. After propranolol, epinephrine reduced oxygen consumption and depressed total blood flow more intensely (Fig. 3 ).

The oxygen-sparing capacity of epinephrine sets it apart from all other vasoconstrictors that we have studied in the canine intestine. It alone could reduce blood flow without impairing oxygen delivery. Unfortunately, epinephrine has other undesirable effects in patients including a vasodilatory action in low doses that could intensify the hemorrhage it was intended to check. Therefore, if gastrointestinal hemorrhage is to be managed effectively with vasoconstrictor drugs, a search should be undertaken to identify a safer drug or drug combination which can also lower intestinal blood flow without depressing oxygen consumption by the gut.

\section{ACKNOWLEDGMENTS}

The authors are grateful to Ms. Paula Leis for technical assistance.

This research was supported in part by U. S. Public Health Service grant AM 15997.

\section{REFERENCES}

1. Conn, H. O., G. R. Ramsby, and E. H. Storer. 1972. Selective intraarterial vasopressin in the treatment of upper gastrointestinal hemorrhage. Gastroenterology. 63 : 634-645.

2. Renert, W. A., K. F. Button, W. J. Casarella, and S. L. Fuld. 1972. Mesenteric venous thrombosis and small bowel infarction following infusion of vasopressin into the superior mesenteric artery. Radiology. 102: 299-302.

3. Johnson, P. C. Autoregulation of intestinal blood flow. 1960. Am. J. Physiol. 199: 311-318.

4. Mellander, S., and B. Johansson. 1968. Control of resistance, exchange, and capacitance functions in the peripheral circulation. Pharmacol. Rev. 20: 117-196.

5. Dresel, P., B. Folkow, and I. Wallentin. 1966. Rubidium $^{88}$ clearance during neurogenic redistribution of intestinal blood flow. Acta Physiol. Scand. 67: 173-184.

6. Cobbold, A., B. Folkow, O. Lundgren, and I. Walletin. 1964. Blood flow, capillary filtration coefficients, and regional blood volume responses in the intestine of the cat during stimulation of the hypothalamic 'defense' area. Acta Physiol. Scand. 61: 467-475.

7. Shepherd, A. P., and H. J. Granger. 1973. Autoregulatory escape in the gut: a systems analysis. Gastroenterology. 65 : 77-91.

8. Granger, H. J., and A. P. Shepherd. 1973. Intrinsic microvascular control of tissue oxygen delivery. Microvasc. Res. 5: 49-72.

9. Shepherd, A. P., D. Mailman, T. F. Burks, and H. J. Granger. 1973. Effects of norepinephrine and sympathetic stimulation on extraction of oxygen and ${ }^{80} \mathrm{Rb}$ in perfused canine small bowel. Circ. Res. 33: 166-174.

10. Shepherd, A. P., D. Mailman, T. F. Burks, and H. J. Granger. 1973. Sympathetic nervous control of intestinal $\mathrm{O}_{2}$ extraction. In Oxygen Transport to Tissue: Instrumentation, Methods, and Physiology. H. I. Bicher and D. F. Bruley, editors. Plenum Publishing Corp., New York. 423-428.

11. Renkin, E. M., and S. Rosell. 1962. The influence of sympathetic adrenergic vasoconstrictor nerves on transport of diffusible solutes from blood to tissues in skeletal muscle. Acta Physiol. Scand. 54: 223-240.

12. Jacobson, E. D., D. Mailman, A. P. Shepherd, and W. Pawlik. 1974. Intestinal ischemia and hypoxia: vasopressin vs. epinephrine. Gastroenterology. 66: 715 (Abstr.)

13. Pawlik, W., A. P. Shepherd, D. Mailman, and E. D. Jacobson. 1974. Effects of ouabain on intestinal oxygen consumption. Gastroenterology. 67: 100-106.

14. Jacobson, E. D., and K. G. Swan. 1966. Hydraulic occluder for chronic electromagnetic blood flow determinations. J. Appl. Physiol. 21: 1400-1402.

15. Jacobson, E. D. 1965. The circulation of the stomach. Gastroenterology. 48: 85-109.

16. Selkurt, E. E. 1971. Peripheral blood pressures and pulses: venous pressure and venous return. In Physiology. E. E. Selkurt, editor. Little, Brown and Company, Boston. 3rd edition. 345-370. 
17. Folkow, B. 1967. Regional adjustments of intestinal blood flow. Gastroenterology. 52: 423-432.

18. Soergel, K. H., G. E. Whalen, J. A. Harris, and J. E. Geenen. 1968. Effect of antidiuretic hormone on human small intestinal water and solute transport. J. Clin. Invest. 47 : 1071-1082.

19. Aulsebrook, K. A. 1961. Effect of vasopressin on sodium transfer by rat colon in vitro. Endocrinology. 68: 10631065. (Abstr.)
20. Parisi, M., and P. J. Bentley. 1970. Effects of vasopressin, cyclic AMP, and theophylline on oxygen consumption of toad bladder 'sacs'. J. Endocrinol. 48: 117124.

21. Blickenstaff, D. D. 1954. Increase in intestinal absorption of water from isosmotic saline following pitressin administration. Am. J. Physiol. 179: 471-472.

22. Zweifach, B. F. 1961. Functional Behavior of the Microcirculation. Charles C. Thomas, Publisher, Springfield, Ill. 